\title{
AVALIAÇÃO DO RISCO AMBIENTAL EM SEDIMENTO DOS LAGOS DO RIACHO CAMBÉ, EM LONDRINA, PELA DISTRIBUIÇÃO DE METAIS
}

\author{
Dílson Norio Ishikawa*, Renata Zacarias Noale, Thiago Hideyuki Kobe Ohe, Eloana Benassi Ribeiro de Souza, Ieda \\ Spacino Scarmínio, Wagner José Barreto e Sônia Regina Giancoli Barreto \\ Departamento de Química, Centro de Ciências Exatas, Universidade Estadual de Londrina, CP 6001, 86051-970 Londrina - PR, \\ Brasil
}

Recebido em 7/7/08; aceito em 3/4/09; publicado na web em 4/9/09

\begin{abstract}
AVALIATION OF THE ENVIRONMENTAL RISK BY METAL DISTRIBUTION IN SEDIMENTS FROM LAKES FORMED BY CAMBÉ STREAM AT LONDRINA. The proposal of this study was to obtain the profile of these metals distribution $\mathrm{Al}, \mathrm{Co}, \mathrm{Cu}, \mathrm{Pb}, \mathrm{Cr}$, $\mathrm{Ni}, \mathrm{Co}$ and $\mathrm{Zn}$ in sediments from lakes in the city of Londrina-PR and evaluate the environmental risk resulting from such distribution. The parameters of comparison were the values of geological occurrence of these metals in soil from this region, the concentrations of metals in soil samples in the surroundings of the sediments collection points, the guiding values from CETESB and resulting rate risk from RAC criterion application. The result shows that the numerical scale RAC alone is incomplete to this evaluation.
\end{abstract}

Keywords: RAC (Risk Assesment Code); sediments; metals distribution.

\section{INTRODUÇÃO}

Estudos acerca dos riscos ambientais vêm sendo desenvolvidos atualmente em vários setores, estando a noção de risco consideravelmente difundida na sociedade, figurando em debates, avaliações e estudos no meio acadêmico e empresarial. Este risco acompanha, via de regra, um adjetivo que o qualifica: risco ambiental, risco social, risco tecnológico, risco natural, biológico, e tantos outros, associados à segurança pessoal, saúde, condições de habitação, trabalho, transporte, ou seja, ao cotidiano da sociedade moderna. ${ }^{1}$

O risco pode ser tomado como uma categoria de análise associada a priori às noções de incerteza, exposição ao perigo, perda e prejuízos materiais, econômicos e humanos em função de processos de ordem natural e/ou daqueles associados ao trabalho e às relações humanas. O risco refere-se, portanto, à probabilidade de ocorrência de processos no tempo e no espaço, não constantes e não-determinados, e à maneira como estes processos afetam (direta ou indiretamente) a vida humana. De maneira geral, poderíamos dizer que a gênese dos riscos, assim como o aumento da capacidade de gerar danos e de sua escala de abrangência, acompanha a história da sociedade. A questão que pode ser colocada, considerando o risco como objeto de investigação científica sistemática, atualmente estudado a partir de bases teóricas e conceituais, é quando e como adquire caráter e status científico.

A noção de risco ambiental, segundo Egler, ${ }^{2}$ foi originalmente sistematizada por Page (1978), quando distinguiu claramente a visão tradicional de poluição do conceito de risco, que está relacionado à incerteza e ao desconhecimento das verdadeiras dimensões do problema ambiental. Page aponta características para sustentar esta separação radical, algumas delas associadas à incerteza dos efeitos futuros de decisões tomadas no presente e outras ligadas à gestão institucional.

A maioria dos trabalhos publicados na literatura que trata de poluição de solo e/ou sedimento por metais, se referindo explicitamente ao termo risco ambiental, é de pesquisadores da área geológica. ${ }^{1-5} \mathrm{Na}$ área da química, apesar da permanente preocupação dos membros da comunidade com esta questão, as referências diretas ao termo "risco ambiental" são menos frequentes. As referências mais comuns dos pesquisadores químicos em relação à poluição de solo e/ou sedimento

\footnotetext{
*e-mail: ishikawa2050@gmail.com
}

por metais traço e metais pesados tóxicos são para a acumulação e disponibilidade de metais, além das condições físico-químicas e biológicas envolvidas que definem a biodisponibilidade.

Em avaliações de disponibilidade de metais pesados tóxicos em solo ou sedimento a concentração total é apenas o ponto de partida dos estudos; essa informação não permite discriminar se os elementos tóxicos em estudo têm origem natural ou antrópica e tampouco sobre mobilidade ou biodisponibilidade. ${ }^{6,7}$ Diferentes amostras que tenham a mesma concentração total de íons de um metal pesado podem variar por um fator de ao menos dez, em termos de toxicidade, para os organismos, associada ao metal. ${ }^{8}$

Uma significativa parte das respostas acerca da mobilidade e disponibilidade dos metais em solos e sedimentos foi dada pelo desenvolvimento de pesquisas em métodos de extração, ${ }^{9-18}$ principalmente das técnicas de extração sequencial que fornecem informações detalhadas acerca da origem, modo de ocorrência, disponibilidade biológica e físico-química, mobilização e transporte de metais traço. Aplicações dessas técnicas na avaliação da distribuição, fracionamento e mobilidade de elementos traço em solos e sedimentos e os estudos de bioacumulação e biodisponibilidade foram e continuam sendo relevantes na produção de conhecimento sobre o comportamento dos metais em solo e sedimento. ${ }^{19-28}$

Singh et al..$^{20}$ e Jain, ${ }^{29}$ além dos estudos sobre distribuição, fracionamento e mobilidade de elementos traços e metais pesados em sedimentos, foram os primeiros pesquisadores da área da química a tratar da poluição ambiental explicitamente com o viés da quantificação, utilizando uma escala numérica para medir o risco ambiental, através do critério RAC (Risk Assessment Code). O ponto de partida para o estabelecimento deste critério foram os estudos de fracionamento de metais em sedimentos do Mar Adriático norte por Perin apud Jain.

A proposta deste trabalho foi obter o perfil de distribuição dos metais $\mathrm{Al}, \mathrm{Co}, \mathrm{Cu}, \mathrm{Cd}, \mathrm{Cr}, \mathrm{Ni}, \mathrm{Pb}, \mathrm{e} \mathrm{Zn}$ em sedimentos de lagos formados ao longo do ribeirão Cambezinho em Londrina - PR e avaliar o risco ambiental desta microbacia decorrente dessa distribuição. Os principais parâmetros de comparação adotados neste estudo foram os valores das concentrações médias dos metais em solo desta região informados pela MINEROPAR, os valores orientadores de intervenção vigentes da CETESB e a taxa de risco resultante da aplicação do critério RAC à distribuição de metais nos sedimentos estudados. ${ }^{30,31}$ 


\section{PARTE EXPERIMENTAL}

Todos os materiais e vidrarias utilizados nos procedimentos foram imersos em $\mathrm{HNO}_{3} 10 \%$ (v/v) por $48 \mathrm{~h}$, enxaguados com água deionizada e secos à temperatura ambiente. Os reagentes usados nas extrações e aberturas de amostras foram de grau analítico (PA). As soluções e amostras foram preparadas com água ultrapura. Os padrões metálicos de estoque (1.000 $\mathrm{mg} \mathrm{L}^{-1}$ ) de $\mathrm{Co}, \mathrm{Cr}, \mathrm{Al}, \mathrm{Cu}$ (Merck), $\mathrm{Ni}, \mathrm{Pb}$, $\mathrm{Zn}$ (Carlo Erba) e Cd (Riedel de Haen) foram preparados diluindo-se o conteúdo das bisnagas, $1.000 \mathrm{mg}$ do metal, para $1 \mathrm{~L}$ com água ultrapura. Os padrões de trabalho foram preparados pela diluição sucessiva dos padrões de estoque, sendo que as medidas foram realizadas em um espectrômetro de emissão atômica com plasma indutivamente acoplado (ICP-AES) da Perkin Elmer Optima 3300 Dv pertencente à EMBRAPA Soja de Londrina - PR.

\section{Área de estudo}

Londrina está localizada no norte do Estado do Paraná, região sul do Brasil. O município de Londrina possui uma farta e bem distribuída rede de drenagem. Os rios do município são todos de caráter perene e escoam sobre o relevo que possui orientação genérica na margem esquerda do Rio Tibagi. Os Lagos Igapó e Cambezinho (localizado no parque Arthur Thomas), pertencem à minibacia do Riacho Cambé que tem à sua esquerda o Ribeirão Limoeiro e, à sua direita, o Ribeirão Três Bocas, do qual é tributário. O Riacho Cambé tem sua nascente no trevo das estradas Londrina/Cambé - São Paulo/ Curitiba (S $23^{\circ} 17^{\prime} 06,5^{\prime \prime}$ - HO 51 $1^{\circ} 14^{\prime} 00,0^{\prime \prime}$ ) recortando a cidade de Londrina no sentido noroeste/sudeste, num percurso de $21,5 \mathrm{~km}$ até desaguar no Ribeirão Três Bocas. ${ }^{32} \mathrm{~A}$ bacia hidrográfica do Ribeirão Três Bocas faz parte da bacia hidrográfica do Rio Tibagi, que se liga às bacias hidrográficas dos Rios Paranapanema, Paraná e finalmente à Bacia Platina. O Lago Igapó, devido à sua fragmentação por ruas e avenidas, foi dividido nos lagos Igapó I, Igapó II, Igapó III e Igapó IV. O parque Arthur Thomas, onde fica localizado o Lago Cambezinho representa um dos últimos remanescentes florestais de Mata Atlântica da região norte do Estado, está localizado no perímetro urbano da cidade, a apenas $6 \mathrm{~km}$ do centro; este se parque caracteriza como uma floresta urbana e nela se encontram várias espécies vegetais nativas, como cedro, figueira, canjarana, pau d'alho, caroba, gurucaia, monjoleiro e aroeira.

Os seis pontos de coletas de sedimentos estão indicados na Figura 1S (Material Suplementar), sendo: ponto 1: foz do Córrego do Rubi no Lago Igapó III; $23^{\circ} 19^{\prime} 06.23$ ” S e 5110'09.20” O; ponto 2: foz do Córrego Água Fresca no Lago Igapó II; $23^{\circ} 19^{\prime} 41.53$ ” S e 51 10'99.76" O; ponto 3: Lago Igapó II (23 19' 41.53” S e 51 10'99.76" O); ponto 4: foz do Córrego do Leme no Lago Igapó I; $23^{\circ} 19^{\prime}$ 52.01" S e 51 09'50.04" O; ponto 5: foz do Córrego Capivara (Baía da Capivara) no Lago Igapó I; 232 20'21.01" S e $51^{\circ}$ 09'44.62" O; ponto 6: Lago Cambezinho (parque Arthur Thomas). $23^{\circ} 20^{\prime} 34.28^{\prime \prime} \mathrm{S}$ e $51^{\circ} 08^{\prime} 27.00^{\prime \prime} \mathrm{O}$.

\section{Coleta e tratamento de amostras}

As amostras de sedimento foram coletadas no mês de março de 2006, com um coletor cilíndrico do tipo gravidade, contendo um tubo de acrílico com 9,0 cm de diâmetro e $50 \mathrm{~cm}$ de comprimento. Os tubos acrílicos, contendo as amostras de sedimento coletadas, foram conservados em caixa térmica até a chegada ao laboratório. Os testemunhos coletados foram cortados em fatias de $5 \mathrm{~cm}$ com auxílio de uma faca inoxidável e levados à estufa para secagem a $50{ }^{\circ} \mathrm{C}$ até atingir massa constante.

As amostras de solo foram coletadas a $20 \mathrm{~cm}$ de profundidade da superfície, em locais adjacentes aos pontos de coleta de sedimentos com auxílio de um trado, transferidas para sacos plásticos e conservadas em caixa térmica até a chegada ao laboratório. Essas amostras foram também secas em estufa a $50{ }^{\circ} \mathrm{C}$ até atingir massa constante.

Após a secagem, as amostras de solo e sedimento foram trituradas em almofariz com auxílio de um pistilo (ambos de porcelana), peneiradas em uma peneira granulométrica de $63 \mu \mathrm{m}$ e armazenadas em frascos plásticos até a determinação de $\mathrm{pH}$ e extrações de metais da fração ácido-solúvel, potencialmente disponível e pseudototal.

\section{Determinação de pH}

A massa de solo seca de $4 \pm 0,2 \mathrm{mg}$ foi transferida para um recipiente plástico e adicionado $10 \mathrm{~mL}$ de água ultrapura obtida no momento da determinação. O conjunto foi agitado mecanicamente por 10 min, deixado em repouso por outros 10 min para sedimentação e, em seguida, introduzidos o eletrodo de vidro e o sensor de temperatura (Hanna modelo HI 9321) ao sobrenadante. As determinações foram realizadas com três repetições.

\section{Métodos de extração de metais de sedimentos e solos}

A fração ácido-solúvel dos metais das amostras foi extraída seguindo o método utilizado por Ure et al.$^{33}$ modificado, usando $1 \pm 0,2$ mg de amostra seca e $40 \mathrm{~mL}$ de ácido acético $0,11 \mathrm{~mol} \mathrm{~L}^{-1}$ padronizado, com agitação por $16 \mathrm{~h}$ a $200 \mathrm{rpm}$. $\mathrm{O} \mathrm{HCl} \mathrm{0,1} \mathrm{mol} \mathrm{L} \mathrm{L}^{-1}$ padronizado foi utilizado para extrair a fração de metais potencialmente disponíveis das amostras de sedimento e solo; para esta extração transferiu-se $1 \pm 0,2 \mathrm{mg}$ de amostra seca para erlenmeyer de $125 \mathrm{~mL}$ e adicionou-se $25 \mathrm{~mL}$ de $\mathrm{HCl}$. As misturas foram submetidas à agitação mecânica por 2 h 30 min em uma mesa agitadora (Nova Ética - modelo 109) a 200 rpm, à temperatura ambiente. Após a agitação as amostras foram filtradas usando-se funil e membrana de filtração com poros de $8 \mu \mathrm{m}$ e diâmetro de 12,5 cm (Quanty ${ }^{\circledR} \mathrm{JP} 42$ - faixa azul) em balões de 50 $\mathrm{mL}$ e completou-se o volume até o menisco.

A concentração pseudototal foi determinada pela digestão das amostras pelo método 3050B da Environmental Protection Agency (EPA). ${ }^{34}$ Os extratos filtrados foram armazenados em frascos de polietileno a $4{ }^{\circ} \mathrm{C}$ até a determinação dos metais por espectrometria de emissão atômica com plasma indutivamente acoplado (ICP-AES). Todas as extrações foram realizadas com três repetições.

\section{RESULTADOS E DISCUSSÃO}

As principais finalidades deste estudo, conforme mencionado anteriormente, foram traçar os perfis de distribuição de metais (Al, $\mathrm{Co}, \mathrm{Cu}, \mathrm{Cd}, \mathrm{Cr}, \mathrm{Ni}, \mathrm{Pb}$, e $\mathrm{Zn}$ ) em amostras de sedimentos dos lagos formados ao longo do Riacho Cambé em Londrina e avaliar a taxa de risco ambiental desses sedimentos.

As taxas de risco ambiental das amostras de solos e sedimentos, para todos os metais, foram calculadas pelo critério RAC, a partir da distribuição do metal específico nas amostras, baseados na fração ácido-solúvel e na concentração pseudototal. De acordo com este critério, as classificações de riscos são indicadas na Tabela 1. Para fins de aplicação deste critério a somatória das frações dos metais trocáveis e associados aos carbonatos, extraídas pelo método de Tessier, ${ }^{9}$ e que representa maior risco ao ambiente, ${ }^{29}$ é a fração de metal disponível. A fração ácido-solúvel do método BCR, segundo Caplat et al..$^{25}$ e Morillo et al. ${ }^{35}$ corresponde à soma das frações trocável e associadas a carbonatos da extração sequencial de Tessier. A maior praticidade para extração da fração disponível pelo método BCR foi determinante para a escolha deste procedimento.

Os metais cromo e níquel não foram detectados nas frações disponível e potencialmente disponível. As concentrações médias de cromo 
e níquel nas amostras de solo e sedimento, pela extração pseudototal, foram 100 e $45 \mathrm{mg} \mathrm{kg}^{-1}$, respectivamente. Esses valores se encontram próximos aos valores de ocorrência geogênica que são $141 \mathrm{mg} \mathrm{kg}^{-1}$ para o Cr e $50 \mathrm{mg} \mathrm{kg}^{-1}$ para o Ni de acordo com a MINEROPAR. Tanto os níveis de ocorrência geogênica como os valores determinados experimentalmente estão acima dos atuais valores de prevenção definidos pela CETESB que são 75 e $30 \mathrm{mg} \mathrm{kg}^{-1}$, respectivamente. As concentrações pseudototais destes elementos são muito similares entre as amostras de solo e sedimento, isso indica que ambos têm origem geológica. E pelo critério RAC, estes metais não representam nenhum risco ao ambiente.

Tabela 1. Critério para avaliação de risco pela fração do metal na fração ácido solúvel (trocável + associada a carbonatos)

\begin{tabular}{lc}
\hline Risco & Critério $(\%)$ \\
\hline Nenhum risco & $<1$ \\
Baixo risco & $1-10$ \\
Médio risco & $11-30$ \\
Alto risco & $31-50$ \\
Altíssimo risco & $>50$ \\
\hline
\end{tabular}

Quanto ao cádmio, este elemento químico não foi detectado em nenhuma das amostras de solo e sedimento estudadas, por nenhum dos três diferentes procedimentos de extração utilizados. O limite de detecção para o Cd por espectrometria de emissão atômica com plasma indutivamente acoplado (ICP) do equipamento, nas condições das leituras, foi de $3 \mathrm{ng} \mathrm{mL}^{-1}$. Sua ocorrência geogênica na região de Londrina é, em média, $0,253 \mathrm{mg} \mathrm{kg}^{-1}$, sendo que o atual de nível de prevenção estabelecido pela CETESB, para este elemento em solo, é $3 \mathrm{mg} \mathrm{kg}^{-1}$. Portanto, também o cádmio não representa qualquer risco ao ambiente nas atuais condições.

Apesar da CETESB não estabelecer nenhum valor orientador para o alumínio em solo, havia interesse na avaliação deste elemento em sedimento devido ao uso de sulfato de alumínio por uma estação de tratamento de água nesta cidade por um longo período, razão pela qual este elemento foi considerado neste trabalho.

Os perfis de distribuição de alumínio nas frações disponível e potencialmente disponível nas amostras de sedimentos e solos são ilustrados na Figura 1. As concentrações médias deste elemento nestas duas frações, 120 e $750 \mathrm{mg} \mathrm{kg}^{-1}$, diferenciam claramente os pontos 2 e 3 dos demais. As concentrações pseudototais de alumínio, por outro lado, cujos valores são muito altos e próximos entre si, seja comparando os diferentes locais de coletas de amostras de sedimentos ou solos, ou as diferentes profundidades de coletas de sedimentos, com valor médio $78.000 \mathrm{mg} \mathrm{kg}^{-1}$, não servem para diferenciar esses locais de coleta.

As classificações de risco das amostras de solo e sedimento em relação ao alumínio, através da porcentagem de alumínio na fração disponível são mostradas na Figura 2. De acordo com o critério RAC todas as fatias do ponto 2 e as fatias $5-10$ e $10-15 \mathrm{~cm}$ do ponto 3 seriam consideradas de baixo risco, enquanto que as demais amostras de sedimento não representariam nenhum risco ao ambiente. De todos os pontos estudados em relação a este elemento, os pontos 2 e 3, do Lago Igapó II, foram os mais críticos, embora a fração disponível tenha sido sempre inferior a 3\% do total. Apesar da classificação baixo risco ou nenhum risco que teriam as amostras de sedimento destes dois pontos de coleta pelo critério RAC, as altas concentrações de alumínio disponível (2.360 mg kg-1) e potencialmente disponível (10.800 $\mathrm{mg} \mathrm{kg}^{-1}$ ) são altamente preocupantes; elas evidenciam a origem antrópica deste metal nesses dois pontos. Essa importante alteração na distribuição do alumínio, no sedimento nos pontos 2 e 3 , foi causada provavelmente pela estação de tratamento de água já mencionada.

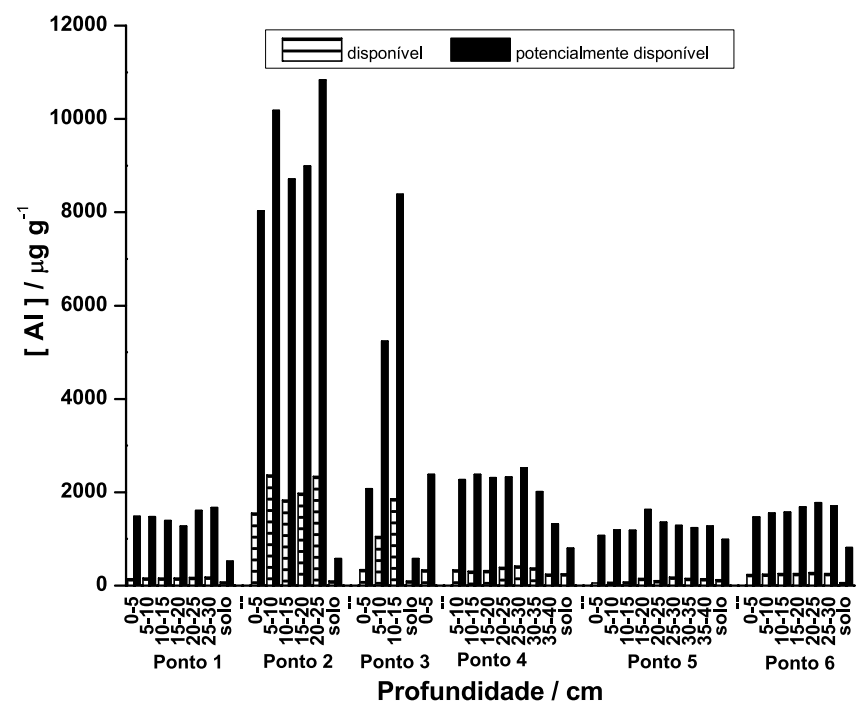

Figura 1. Perfis de distribuição de alumínio em solos e sedimentos (por fatias). Ponto 1: Foz do Córrego Rubi-Lago Igapó III; Ponto 2: foz do Córrego Água Fresca-Lago II; Ponto 3- Lago Igapó II; Ponto 4: foz do Córrego do Leme-Lago Igapó I; Ponto 5: foz do Córrego Capivara-Lago Igapó I; Ponto 6: Lago Cambezinho

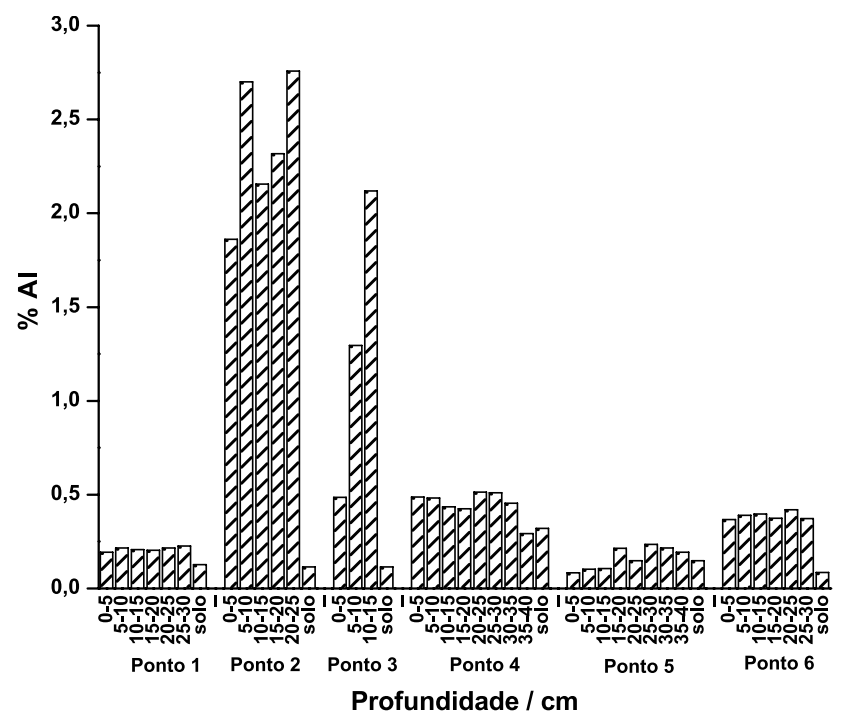

Figura 2. Porcentagem de alumínio em solos e sedimentos (por fatias) na fração ácido-solúvel (disponível). Ponto 1: Foz do Córrego Rubi-Lago Igapó III; Ponto 2: foz do Córrego Água Fresca-Lago II; Ponto 3- Lago Igapó II; Ponto 4: foz do Córrego do Leme-Lago Igapó I; Ponto 5: foz do Córrego Capivara-Lago Igapó I; Ponto 6: Lago Cambezinho

Os perfis de distribuição de zinco e chumbo nas frações disponível e potencialmente disponível, juntamente com as concentrações pseudototais destes elementos, são mostrados na Figura 3, enquanto que as porcentagens destes metais na fração disponível são informadas na Figura 4. As concentrações disponível, potencialmente disponível e pseudototal de cobalto e cobre nas amostras estudadas encontram-se na Figura $2 \mathrm{~S}$ (Material Suplementar) e as percentagens destes metais determinadas na fração ácido solúvel na Figura 3S (Material Suplementar).

As concentrações pseudototais médias de cobalto encontradas nas amostras de solo e sedimento foram 47 e $35 \mathrm{mg} \mathrm{kg}^{-1}$, respectivamente, sendo que nas amostras de solo dos pontos 1 (Lago Igapó III) e 6 (parque Arthur Thomas), os valores foram 62 e $60 \mathrm{mg} \mathrm{kg}^{-1}$. Com exceção desses dois locais, os níveis de cobalto encontrados em solo 

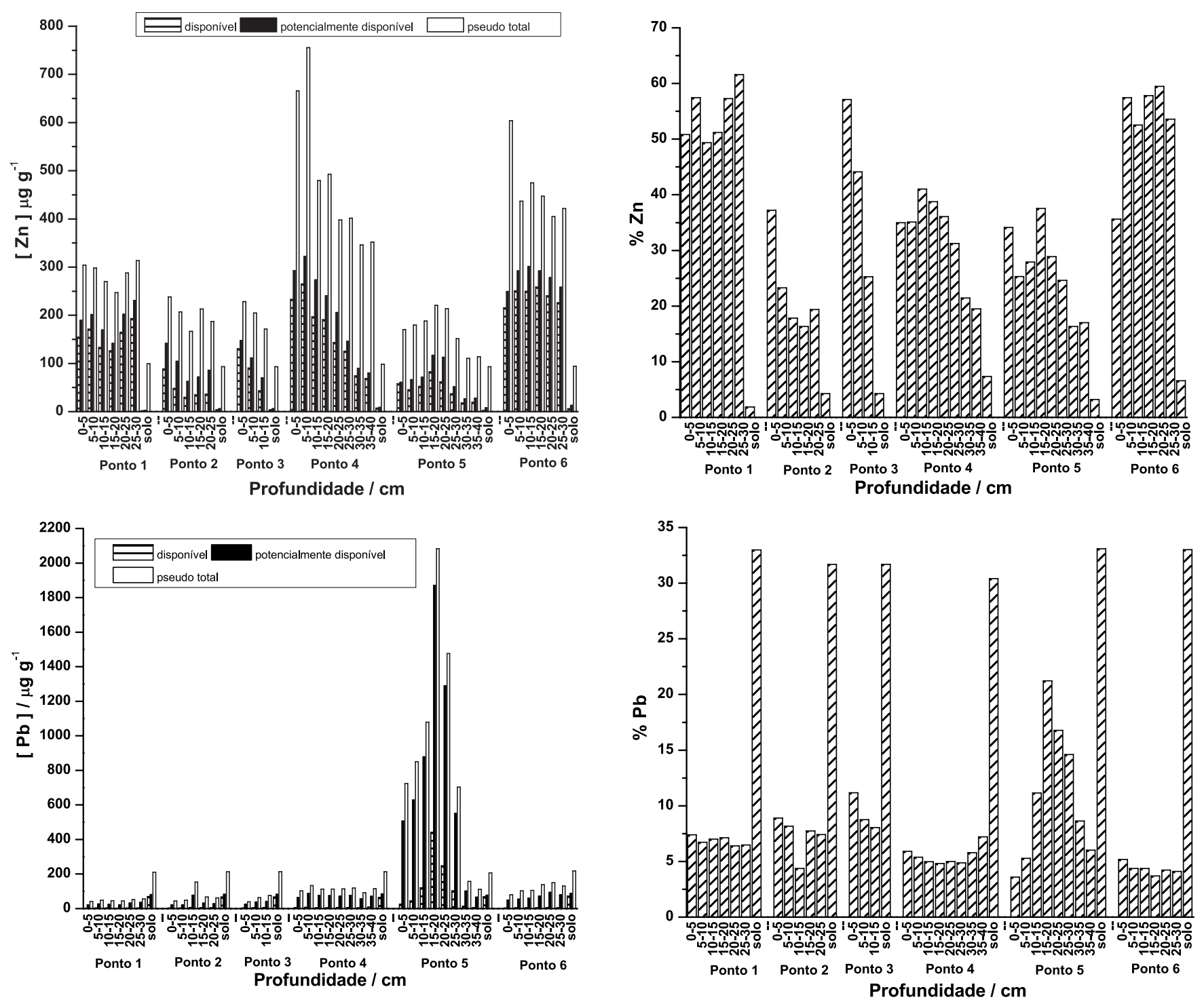

Figura 3. Perfis de distribuição de zinco e chumbo em solos e sedimentos (por fatias). Ponto 1: Foz do Córrego Rubi-Lago Igapó III; Ponto 2: foz do Córrego Água Fresca-Lago II; Ponto 3- Lago Igapó II; Ponto 4: foz do Córrego do Leme-Lago Igapó I; Ponto 5: foz do Córrego Capivara-Lago Igapó I; Ponto 6: Lago Cambezinho

e sedimento estão mais próximos da ocorrência geológica na região de Londrina, que é de $45 \mathrm{mg} \mathrm{kg}^{-1}$ de acordo com a MINEROPAR. Tanto os valores experimentais para solo e sedimento, quanto o valor informado pela MINEROPAR para este elemento em solo na região de Londrina, são superiores ao atual valor estabelecido pela CETESB para nível de prevenção em solos $\left(25 \mathrm{mg} \mathrm{kg}^{-1}\right)$. Aplicando-se o critério $\mathrm{RAC}$ aos valores experimentalmente determinados para o cobalto em amostras de sedimento, obtêm-se as classificações de médio a alto risco. Em relação ao cobalto, as amostras de solo são de baixo risco em todos os pontos, exceto ponto 4 (Lago Igapó I) que deve ser considerado de médio risco; esta classificação pode ser atribuída à maior acidez do solo neste ponto ( $\mathrm{pH} 4,86)$, o mais baixo entre os pontos coletados (Tabela 2).

Na Figura 2S (Material Suplementar) nota-se que apesar das concentrações pseudototais de cobalto nas amostras de solo (exceto pontos 1 e 6) e sedimento serem próximas entre as diferentes matrizes, as classificações pelo critério RAC foram de maior risco para os sedimentos do que para os solos. Estes resultados se devem à maior

Figura 4. Porcentagem de zinco e chumbo na fração ácido-solúvel (disponível) para amostras de solos e sedimentos (por fatias). Ponto 1: Foz do Córrego Rubi-Lago Igapó III; Ponto 2: foz do Córrego Água Fresca-Lago II; Ponto 3- Lago Igapó II; Ponto 4: foz do Córrego do Leme-Lago Igapó I; Ponto 5: foz do Córrego Capivara-Lago Igapó I; Ponto 6: Lago Cambezinho

Tabela 2. Valores experimentais de $\mathrm{pH}$ para amostras de solos

\begin{tabular}{ll}
\hline Pontos de Coleta & $\mathrm{pH}$ \\
\hline Ponto 1 - Igapó III & 5,52 \\
Ponto 2 - Igapó II & 5,31 \\
Ponto 3 - Igapó II & 5,31 \\
Ponto 4 - Igapó I - foz Leme & 4,86 \\
Ponto 5 - Baía Capivara & 6,54 \\
Ponto 6 - Pq. Arthur Thomas & 6,46 \\
\hline
\end{tabular}

disponibilidade de cobalto nas amostras de sedimento do que no solo, indicando que este metal em sedimento pode ter origem antrópica e/ ou que o sedimento sofreu alguma ação que deve ter alterado alguma propriedade físico-química dessa matriz.

O nível de ocorrência natural de cobre em solo na região de Londrina é $250 \mathrm{mg} \mathrm{kg}^{-1}$ de acordo com a MINEROPAR e o valor 
médio encontrado nas amostras de solo e sedimento pela extração pseudototal foi $270 \mathrm{mg} \mathrm{kg}^{-1}$, ambos superiores ao valor de prevenção estabelecido pela CETESB para solo que é $60 \mathrm{mg} \mathrm{kg}^{-1}$.

As concentrações pseudototais de cobre em solo e sedimento foram muito similares em todos os pontos avaliados. Porém, as frações de cobre disponível e potencialmente disponível em todas as amostras de solo foram, com exceção do ponto 2 na fração disponível, bastante inferiores aos das amostras de sedimentos, indicando que o cobre nas amostras de sedimento pode ter origem antrópica. A fração de cobre disponível na amostra de solo do ponto 4 foi 11 $\mathrm{mg} \mathrm{kg}^{-1}$, pelo menos $50 \%$ a mais nesta fração em comparação aos demais pontos para solo, comprovando, uma vez mais, a importante influência que o $\mathrm{pH}$ exerce na alteração da disponibilidade deste metal (Tabela 2).

Concentrações mais elevadas de cobre disponível, ultrapassando $30 \mathrm{mg} \mathrm{kg}^{-1} \mathrm{em}$ amostras de sedimento foram determinadas em todas as fatias dos pontos 1 e 4 , na fatia $0-5 \mathrm{~cm}$ do ponto 3 , fatias $15-20 \mathrm{e}$ $25-30 \mathrm{~cm}$ do ponto 5 e fatias $15-20$ até $25-30 \mathrm{~cm}$ do ponto 6 . O ponto 2 (Lago Igapó II) foi dentre todos o local que acusou a mais baixa concentração de cobre disponível.

Ainda em relação ao cobre em solo, o ponto 6 é classificado de nenhum risco e os demais pontos são de baixo risco. As amostras de sedimento dos pontos 1 (todas as fatias), ponto 3 (0-5 e 5-10 $\mathrm{cm})$, ponto 4 , ponto $5(15-20$ a $35-40 \mathrm{~cm})$ e ponto $6(15-20$ a $25-30$ $\mathrm{cm})$ são classificadas de médio risco e as demais fatias são de baixo risco. É importante frisar que o valor de referência de qualidade da CETESB para cobre em solo é $35 \mathrm{mg} \mathrm{kg}^{-1}$, enquanto que os sedimentos classificados em baixo ou médio risco podem disponibilizar até $47 \mathrm{mg} \mathrm{kg}^{-1}$.

$\mathrm{O}$ valor médio para ocorrência natural de zinco em solo na região de Londrina é da ordem de $111 \mathrm{mg} \mathrm{kg}^{-1}$ segundo a MINEROPAR. A concentração pseudototal máxima deste elemento encontrada em amostras de solo de Londrina foi 99,5 mg kg-1 e a mínima 93,11 mg $\mathrm{kg}^{-1}$. A fração máxima disponível deste elemento no solo alcança $7,34 \%$ e a classificação para todas as amostras é de baixo risco. $\mathrm{O}$ valor de prevenção para o zinco em solo estabelecido pela CETESB é $300 \mathrm{mg} \mathrm{kg}^{-1}$, comprovando que este metal para os pontos de solo amostrados não representa qualquer risco ao ambiente.

As concentrações pseudototais de zinco nos sedimentos foram bastante superiores às determinadas nas amostras de solo e também superiores ao nível de ocorrência geológica relatado pela MINEROPAR. Nos pontos 4 (Igapó I) e 6 (parque Arthur Thomas) a concentração pseudototal de zinco no sedimento, em todas as fatias, foi superior ao valor de prevenção da CETESB. Um aspecto que chama atenção no caso deste elemento químico, avaliando-se a distribuição pseudototal por fatias, é que a deposição do zinco está aumentando com o decorrer do tempo praticamente em todos os pontos amostrados.

Aplicando-se o critério RAC para avaliar o sedimento por fatias em relação ao zinco, nota-se que praticamente todas as fatias dos pontos 1 e 6 são classificadas como de altíssimo risco, enquanto que todas as fatias dos pontos 2 , 4 e 5 são classificadas como de médio a alto risco. O sedimento do ponto 3 , apesar de contar com a coluna de sedimento de menor profundidade, foi o que apresentou maior variação do ponto de vista de risco ambiental, variando de médio risco para a fatia mais profunda $(10-15 \mathrm{~cm})$, alto risco na fatia intermediária (5-10 cm) e altíssimo risco para a fatia mais superficial $(0-5 \mathrm{~cm})$.

A alta concentração de zinco e a alta disponibilidade deste metal no sedimento, em comparação ao solo adjacente, comprovam a origem antrópica deste metal e demonstram que os metais presentes nos sedimentos têm origem antrópica e são mais disponíveis do que aquelas de origem geológica.

A ocorrência natural de chumbo em solo na região de Londrina é da ordem de $19 \mathrm{mg} \mathrm{kg}^{-1}$ conforme a MINEROPAR. Nos seis locais de solo amostrados a concentração pseudototal média determinada foi $212 \mathrm{mg} \mathrm{kg}^{-1}$; este valor é pelo menos onze vezes superior ao de ocorrência natural. Essa concentração ultrapassa o valor de prevenção estabelecido pela CETESB que é de $72 \mathrm{mg} \mathrm{kg}^{-1}$ para este elemento em solo. A concentração média de chumbo disponível nos solos para esses mesmos locais foi da ordem de $68 \mathrm{mg} \mathrm{kg}^{-1}$, valor que pelo critério RAC classifica todos os pontos amostrados em alto risco.

Em relação aos sedimentos, as concentrações pseudototais de chumbo encontradas nos pontos 1, 2, 3, 4 e 6 são menores que as dos solos adjacentes para todas as fatias avaliadas, porém os valores encontrados em todas as amostras são superiores ao de ocorrência geológica. Dos locais amostrados os sedimentos dos pontos 4, 5 e 6 foram os que apresentaram níveis mais elevados de chumbo, embora apenas no ponto 5 (Baía Capivara) a concentração pseudototal de chumbo foi mais elevada no sedimento do que no solo adjacente. Neste ponto também foram determinadas as mais altas taxas de risco para o chumbo, dentre todos os locais amostrados, sendo que a fatia $15-20 \mathrm{~cm}$ é classificada em médio risco e as demais fatias são classificadas em baixo risco.

A classificação da fatia $15-20 \mathrm{~cm}$ em médio risco pelo critério RAC, porém, não é compatível sob vários aspectos. A concentração de chumbo disponível nesta fatia é superior a $440 \mathrm{mg} \mathrm{kg}^{-1}$, enquanto que a concentração pseudototal é de $2.082 \mathrm{mg} \mathrm{kg}^{-1}$; isso significa que a concentração passível de disponibilização ao ambiente é pelo menos 6 vezes superior ao valor de prevenção proposto pela CETESB. A fração de chumbo potencialmente disponível, ou seja, o percentual de chumbo presente no sedimento que pode ser disponibilizada ao ambiente por alterações mais bruscas nas condições ambientais, eleva consideravelmente o risco ambiental devido ao sedimento da Baía Capivara. Especificamente para a fatia $15-20 \mathrm{~cm}$ deste ponto, $1.871 \mathrm{mg} \mathrm{kg}^{-1}$ de chumbo que corresponde a $90 \%$ de $\mathrm{Pb}$ acumulado, pode ser disponibilizado.

Um aspecto interessante na distribuição de chumbo por fatia de sedimento relativo ao ponto 5, Baía Capivara, está na distribuição deste elemento; a concentração deste metal aumenta na medida em que aumenta a profundidade do sedimento até $15-20 \mathrm{~cm}$ (maior contaminação) e reduz a partir desta fatia até $35-40 \mathrm{~cm}$. O sedimento deste ponto é um registro histórico de um período de atividades de uma fábrica de baterias, pois ao observar a distribuição de chumbo a partir da fatia de maior profundidade até a mais superficial, nota-se inicialmente o aumento na concentração de chumbo indicando aumento no lançamento de efluentes industriais (aumento das atividades industriais) até a fatia $15-20 \mathrm{~cm}$; a partir desta fatia observa-se a diminuição na concentração deste metal, indicando redução no lançamento de efluentes. A redução na concentração de chumbo nas fatias mais superficiais, a partir de $15-20 \mathrm{~cm}$, pode estar relacionada ao maior rigor na legislação ambiental ou também à diminuição nas atividades industriais da fábrica de baterias, hoje praticamente inativa.

\section{CONCLUSÕES}

A distribuição de alumínio nas frações disponível e potencialmente disponível em sedimentos dos pontos 2 e 3 comprovam que os metais com origem antrópica são mais disponíveis que aqueles de ocorrência natural.

A utilização da escala numérica RAC para medir o risco ambiental em solo e/ou sedimento facilita a comparação entre diferentes elementos e locais, evidenciando diferenças nas mobilidades dos íons metálicos em compartimentos impactados.

Os resultados mostram que isoladamente a escala numérica RAC para medir o risco ambiental é insuficiente e necessita de um complemento em sua definição para ser adotada como um indicador eficiente e seguro. A classificação de risco do sedimento ou solo, além das percentagens do metal disponível presente na fração ácido 
solúvel (RAC), deve considerar, também, uma concentração total de referência para cada metal, por exemplo, a concentração de alerta da CETESB.

\section{MATERIAL SUPLEMENTAR}

Encontra-se disponível em http://quimica.nova.org.br em arquivo pdf, com acesso gratuito, o seguinte material: Figura $1 \mathrm{~S}$ - Principais represas formadas ao longo do Riacho Cambé, com indicação dos locais de coleta; Figura $2 \mathrm{~S}$ - Perfis de distribuição de cobalto e cobre em solos e sedimentos (por fatias) e Figura $3 \mathrm{~S}$ - Porcentagens de cobalto e cobre na fração ácido-solúvel (disponível) em amostras de solo e sedimentos (por fatias).

\section{REFERÊNCIAS}

1. Castro, C. M.; Peixoto, M. N. O.; Pires do Rio, G. A.; Anuário do Instituto de Geociências, Rio de Janeiro, 2005, 28, 11.

2. Egler, C. A. G.; Território 1996, 1, 31.

3. Lourenço, R. W; Landim, P. M. B.; Caderno de Saúde Pública 2005, 21, 150.

4. Robaina, L. E.; Formoso, M. L. L.; Pires, C. A.; Revista do Instituto Geológico, São Paulo, 2002, 23, 35.

5. Pires, P. C. M.; Dissertação de Mestrado, Universidade Nova de Lisboa, Portugal, 2006.

6. Adamo, P.; Arienzo, M.; Imnperato, M.; Naimo, D.; Nardi, G.; Stanzione, D.; Chemosphere 2005, 61, 800.

7. Gardolinski, P. C. F. C.; Packer, A. P.; Almeida, C. R.; Fernanda Giné, M.; J. Braz. Chem. Soc. 2002, 13, 375.

8. Baird, C.; Química Ambiental, 2ª ed.; Bookman: Porto Alegre, 2002.

9. Tessier, A.; Campbell, P. G. C.; Bisson, M.; Anal. Chem. 1979, 51, 844.

10. Gleyzes, C.; Tellier, S.; Astruc, M.; Trends Anal. Chem. 2002, 21, 451.

11. Jocsic, A. S.; Katz, S. A.; Horvat, T, M.; Milacic, R.; Water, Air, Soil Pollut. 2005, 162, 265.

12. Kimbrough, D. E.; Wakakuwa, R.; Environ. Sci. Technol. 1989, 23, 898.

13. Gismera, M. J.; Lacal, J.; Silva, P.; Garcia, R.; Sevilla, T.; Procopio, J. R.; Environ. Pollut. 2004, 127, 175.

14. Lã, O. R.; Barra, C. M.; do Amaral Sobrinho, N. M. B.; Mazur, N.; Velloso, A. C. X.; Quim. Nova 2003, 26, 323.

15. Fernandes Alborés, A.; Perez Cid, B.; Fernandez Gomez, E.; Falque Lopes, E.; Analyst 2000, 125, 1353.
16. Pardo, R.; Helena, B. A.; Cazurro, C.; Guerra, C.; Deban, L.; Guerra, C. M.; Vega, M.; Anal. Chim. Acta. 2004, 523, 125.

17. DePaula, F. C. F; Mozeto, A. A.; Appl. Geochem. 2001, 16, 1139.

18. Barreto, S. R. G.; Nozaki, S. R. G.; Oliveira, E.; Nascimento Filho, V. F.; Aragão, P. H. A.; Scarmínio, I. S.; Barreto, W. J.; Talanta 2004, 64, 345.

19. El-Azim, H. A.; El-Moselhy, Kh. M.; J. Mar. Sys. 2005, 56, 363.

20. Singh, K. P.; Mohan, D.; Singh, V. K.; Malik, A.; J. Hydrol. 2005, 312, 14.

21. El Bilali, A.; Rasmussen, P. E.; Hall, G. E. M.; Fortín, D.; Appl. Geochem. 2002, 17, 1171.

22. Monterroso, P.; Pato, P.; Pereira, E.; Vale. C.; Duarte, A. C.; Mar. Pollut. Bull. 2003, 46, 1200.

23. Pereira, J. C.; Guimarães-Silva, A. K.; Nalini Jr., H. A.; Pacheco-Silva, E.; Lena, J. C.; Quim. Nova 2007, 30, 1249.

24. Chandra Sekhar, K.; Chary, N. S.; Kamala, C. T.; Suman Raj, D. S.; Sreenivasa Rao, A.; Environ. Int. 2003, 29, 1001.

25. Caplat, C.; Texier, H.; Barillier, D.; Lelievre, C.; Mar. Pollut. Bull. 2005, $50,504$.

26. Borgmann, U.; Aquat. Ecosys. Health Managm. 2000, 3, 277.

27. Sabino, C. V. S.; Kastner, G. F.; Amaral, A. M.; Leite, S. C. A. L.; Carvalho, R. P.; Silva, I. R.; Quim. Nova 2004, 27, 231.

28. Deheyn, D. D.; Latz, M. I.; Chemosphere 2006, 63, 818.

29. Jain, C. K.; Water Res. 2004, 38, 569.

30. Minerais do Paraná S.A (MINEROPAR); Geoquímica de solo do Estado do Paraná - Horizonte B: Relatório final de projeto, Curitiba, 2005, 2.

31. Companhia de Tecnologia de Saneamento Ambiental (CETESB); Relatório de estabelecimento de valores orientadores para solos e água subterrânea no Estado de São Paulo, São Paulo, 2005.

32. Tagima, N.; Terabe, N. I.; Minibacia do riacho Cambé diagnóstico físico-ambiental e mapeamento detalhado de solos, Universidade Estadual de Londrina, Departamento de Geociências, Londrina - PR, 2005.

33. Ure, A. M.; Quevauviller, P.; Muntau, H.; Griepink, B.; Int. J. Environ. Anal. Chem. 1993, 51, 135.

34. U.S. Environmental Protection Agency; Method 3050B: acid digestion of sediments, sludges and soils. Dec. 1996, disponível em: http://www. epa.gov/waste/hazard/testmethods/sw846/pdfs/3050b.pdf, acessada em Agosto 2009.

35. Morillo, J.; Usero, J.; Gracia, I.; Environ. Int. 2002, 28, 263. 


\section{AVALIAÇÃO DO RISCO AMBIENTAL EM SEDIMENTO DOS LAGOS DO RIACHO CAMBÉ, EM LONDRINA, PELA DISTRIBUIÇÃO DE METAIS}

Dílson Norio Ishikawa*, Renata Zacarias Noale, Thiago Hideyuki Kobe Ohe, Eloana Benassi Ribeiro de Souza, Ieda Spacino Scarmínio, Wagner José Barreto e Sônia Regina Giancoli Barreto

Departamento de Química, Centro de Ciências Exatas, Universidade Estadual de Londrina, CP 6001, 86051-970 Londrina - PR, Brasil

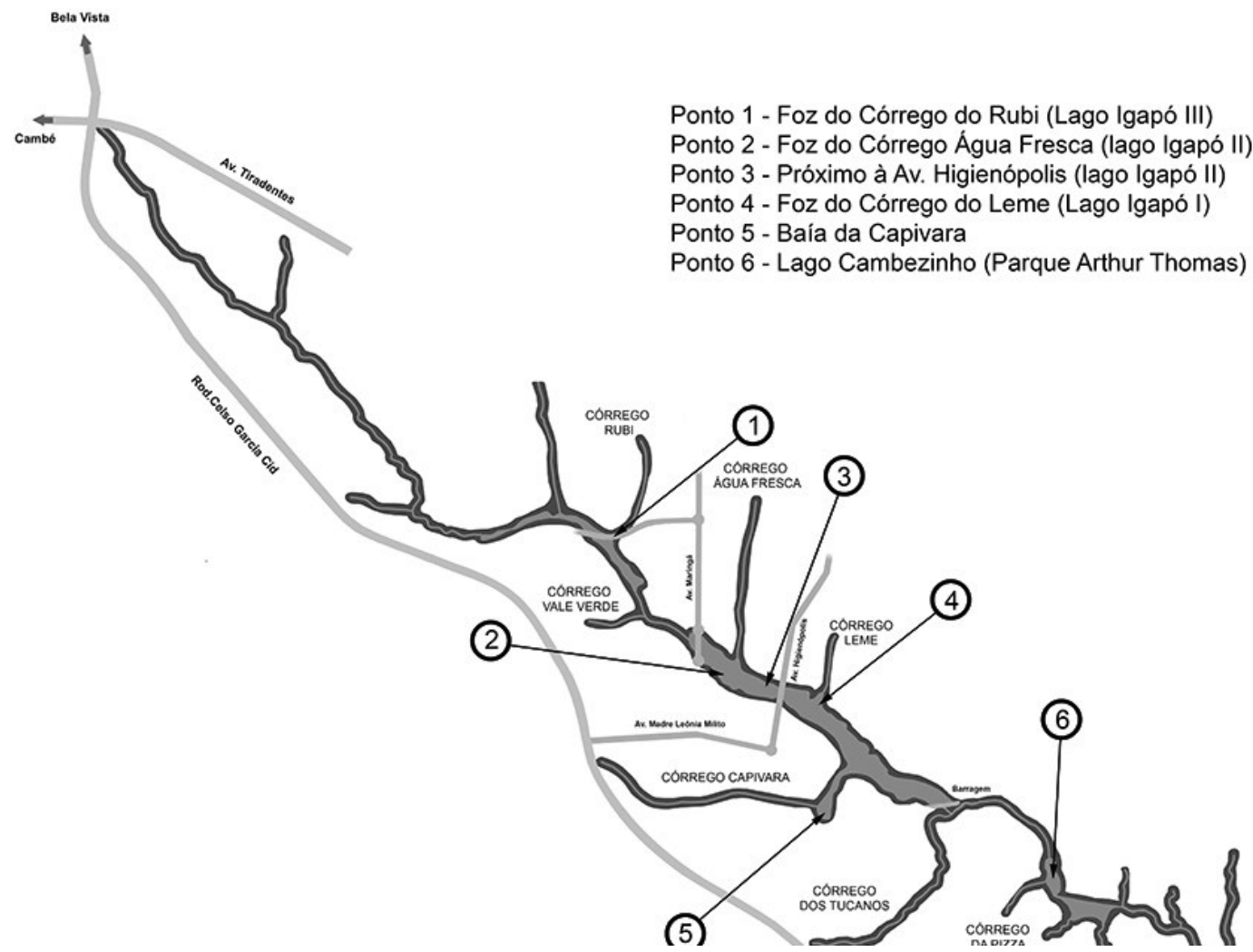

Figura 1S. Principais represas formadas ao longo do Riacho Cambé, com indicação dos locais de coleta 

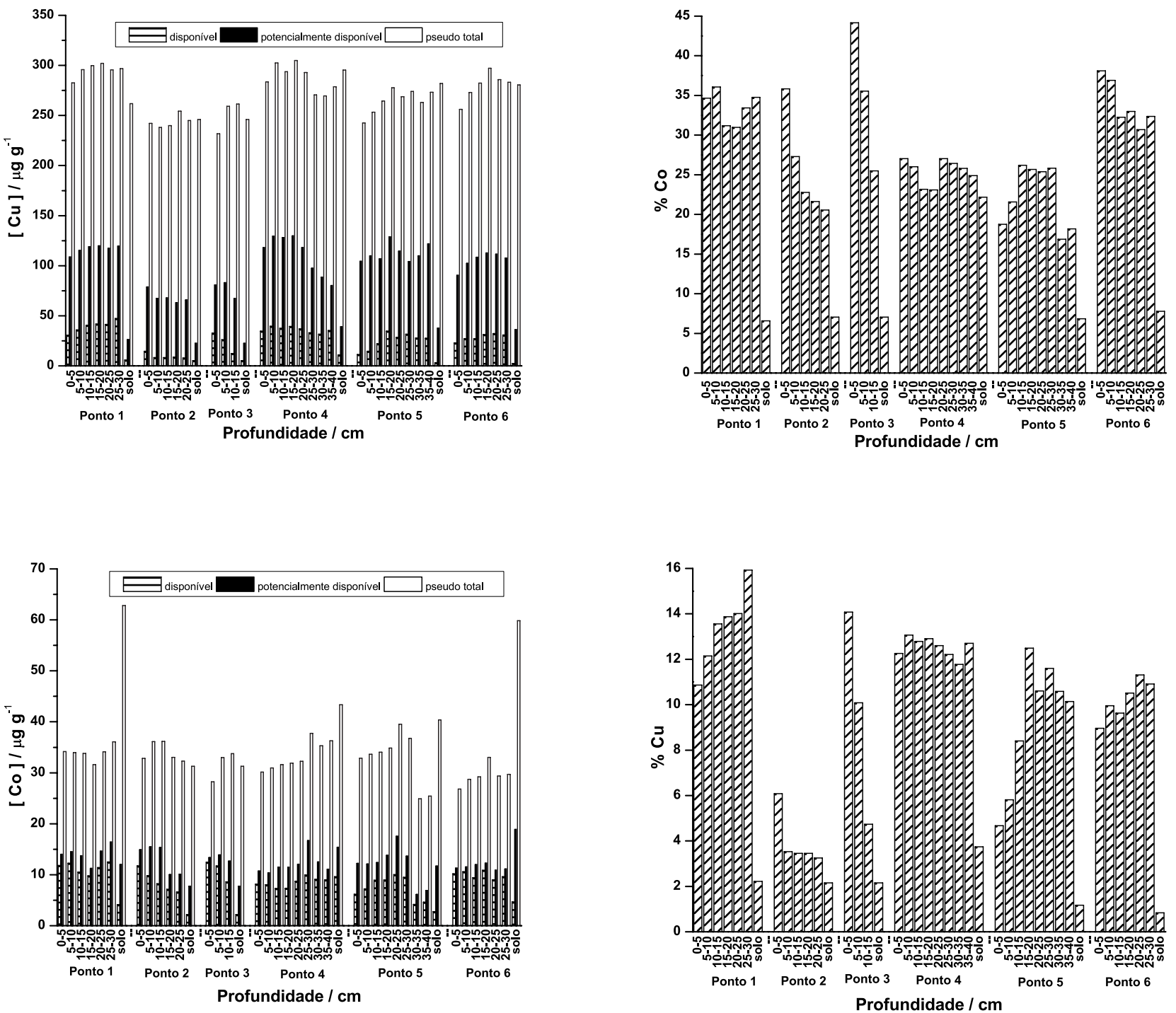

Figura 2S. Perfis de distribuição de cobalto e cobre em solos e sedimentos (por fatias). Ponto 1: Foz do Córrego Rubi-Lago Igapó III; Ponto 2: foz do Córrego Água Fresca-Lago II; Ponto 3- Lago Igapó II; Ponto 4: foz do Córrego do Leme-Lago Igapó I; Ponto 5: foz do Córrego Capivara-Lago Igapó I; Ponto 6: Lago Cambezinho

Figura 3S. Porcentagem de cobalto e cobre na fração ácido-solúvel (disponível) em amostras de solo e sedimentos (por fatias). Ponto 1: Foz do Córrego Rubi-Lago Igapó III; Ponto 2: foz do Córrego Água Fresca-Lago II; Ponto 3- Lago Igapó II; Ponto 4: foz do Córrego do Leme-Lago Igapó I; Ponto 5: foz do Córrego Capivara-Lago Igapó I; Ponto 6: Lago Cambezinho 